\title{
The USE OF ACTIVITY-BASEd COSTING In SOUTH African Private Health CaRe Industry
}

\author{
Gideon Botha* \\ University of Pretoria \\ Gbotha1234@gemail.com
}

Received: May 2014

\author{
Frans Vermaak" \\ University of Pretoria \\ Frans.vermaak@up.ac.za
}

Accepted: June 2015

\begin{abstract}
The private health care industry is facing uncertainty and change as a result of the market inquiry being undertaken by the Competition Commission into the private health care industry, the introduction of the National Health Insurance and the possibility of fee regulation. This study seeks to determine the extent to which activity-based costing is used within the operations of private health care facilities in South Africa. A structured online questionnaire was used to collect the primary data; it was completed by 32 private health care facilities and three hospital groups. This study found that the level of activity-based costing adoption at a health care facility level increased from $1.2 \%$ in 1994 to $31 \%$ in 2013 . The increase in the level of activity-based costing adoption indicates that the private health care facilities are willing to adopt and use innovative management tools and techniques to face their current challenges.
\end{abstract}

Keywords

Activity-based costing, National Health Insurance, private health care industry, South Africa, Competition Commission

*Mr G Botha is a master's student in the Department of Financial Management, University of Pretoria, South Africa.

\#Prof F Vermaak is an associate professor in the Department of Financial Management, University of Pretoria, South Africa. 


\section{INTRODUCTION}

In South Africa, $8.5 \%$ of the country's gross domestic product (GDP) is currently spent on health expenditure (this includes both the public and private health sector). Around $5 \%$ of the GDP is spent on private health care, which services about 7 million people, and the remaining $3.5 \%$ caters for the other 41 million people who are dependent on the public health care sector (Bateman, 2010:352). This exceeds the recommendation of the World Health Organisation that advises that a country should spend around $5 \%$ of its GDP on health care (Department of Health, 2011:9).

In order to bridge the gap between the private and public health care systems, the South African government has decided to phase in the National Health Insurance ( $\mathrm{NHI}$ ) over the next few years. The NHI aims to improve access to quality health services, pool the risks into a single health fund, procure services on behalf of the entire population in order to efficiently mobilise and control financial resources, and strengthen the public health sector (Matsoso \& Fryatt, 2013:156). The NHI will be financed through a special NHI tax of between $3.5 \%$ and $5 \%$ levied on wages/salaries (Wasserman, 2010:1). The impact that this special tax will have on the number of people with private medical insurance will only be determined when the NHI tax has been introduced.

Over the past decade, private health care costs have increased by 121\% (Bateman, 2010:352), which led to the Competition Commission launching an inquiry into the private health care industry (Bateman, 2013:278). The Competition Commission has a broad scope and the power to summon anyone who could provide information that may assist in establishing what is driving up the fees in the private health care industry (Bateman, 2013:278). On completion of the inquiry, recommendations will be made. These recommendations will become policy to regulate and support affordable and quality health care and acceptable price-setting mechanisms (Makholwa, 2013a:36).

The Minister of Health, Dr Aaron Motsoaledi, has further proposed to regulate prices through a health commission, which will be a statutory body. This will be dependent on the outcomes of the Competition Commission's inquiry (Makholwa, 2013b:36).

The climate of uncertainty and change within the private health care industry makes this the ideal time to adopt new management tools and techniques such as activity-based costing $(A B C)$. Since 1994, changes in management accounting in South Africa have been driven by increased uncertainty about the economic environment, a shortage in the availability of competent staff, the removal of barriers to trade, and the increased cost of input (Luther \& Longden 2001:313). This proves that the private health care industry is ideally suited to make management accounting changes in order to improve efficiencies in its operations.

\section{LITERATURE REVIEW}

\subsection{Background to the development of $A B C$}

During the 1980s, the increase in global competition and the rise in costs due to misleading cost information and performance measures led to traditional product costing's limitation being placed in the spotlight (Holzer \& Norreklit, 1991:273). Traditional product costing systems were designed when companies had small product ranges, very simple product mixes, and most of the 
product costs were direct in nature with very little overhead costs. In the 1980s, however, the number of products in a given product line vastly increased. During the 1960s in the USA, overhead costs represented $15 \%$ of total products manufacturing costs. By the late 1990s, overhead costs had risen to $35 \%$ of total products manufacturing costs (Correia, LangfieldSmith, Thorne \& Hilton, 2008:351). Direct labour costs in the USA fell from 25\% in the 1960 s to $10 \%$ of product costs during the 1990s (Correia et al., 2008:351). The increase in overhead costs, decrease in direct labour costs, and increase in product lines forced businesses to develop more complex costing systems in order to improve the accuracy of the costing information (Cooper \& Kaplan, 1988:1).

The increase in the cost of inaccurate costing information and the decrease in the cost of operating more complex cost systems created a demand for more accurate product costing systems to be developed. Against this backdrop ABC was developed (Holzer \& Norreklit, 1991:276).

As early as 1949 , Goetz identified and advocated the principles of $A B C$ when he wrote that each overhead category should be uniform with respect to every significant element of management problems and control. Some of the elements along which overheads may fluctuate are the number of units output, number of operations, capacity of the plant and the number of different products offered (Drury, 2004:375).

Also, General Electric's finance team applied the principles of $A B C$ during the 1960 s in an attempt to improve the usefulness of accounting information in conjunction with controlling the ever-increasing indirect costs. The staff noted that indirect costs are often the result of 'upstream' decisions that are made long before the costs are actually incurred (McConville, 1993:36).

The ideas and principles of $A B C$ were conceptualised by Cooper and Kaplan in an article published in 1988 and a series of further articles were then published on the subject (Lukka \& Granlund, 2002:171).

\section{2 $\mathrm{ABC}$ in the service industry}

Cooper and Kaplan (1998:231) suggest that the service industry is better suited to ABC adoption and will benefit more from the adoption thereof than the manufacturing industry. This is because the majority of service costs are indirect in nature, whereas the manufacturing industry has a much smaller portion of indirect costs in relation to direct costs.

Strong competition for existing services, globalisation and deregulation has brought about a further need to improve profitability and the quality of service costing information. As the service industry is also more labour intensive than the manufacturing industry, more activities and cost pools will be used to render the service. This increases the importance to accurately measure the cost of each activity and to understand the cause-and-effect relationship that exists between activities and the cost incurred to render the service (Clarke \& Mullins, 2001:5).

\subsection{ABC in South Africa}

The first survey conducted in South Africa to determine the adoption rate of $A B C$ was done by Wessels (1999:43), who found that only 15.18\% of listed companies in South Africa have attempted to implement $A B C$. Results obtained by Jacobs (2005:123) showed that $32 \%$ of the listed companies adopted $A B C$, which demonstrates a growth of $16.82 \%$ over a six-year period. 
The survey results of Jacobs (2005:123) are further supported by Waweru, Hoque and Uliana (2005:239), who also found that $32 \%$ of listed companies had adopted ABC. The survey was conducted in 2001. However, the latest survey conducted by Sartorius, Eitzen and Kamala (2007:5) found the rate of $A B C$ adoption to be $12 \%$ of listed companies. This survey found that $57 \%$ of the goods sector respondents; $19 \%$ of the resource sector respondents; $13 \%$ of the financial services respondents; and $12 \%$ of the basic industry respondents had adopted $A B C$ (Sartorius et al., 2007:5). These results support the result obtained by Wessels (1999:43), but contradict the results of Jacobs (2005:123) and Waweru et al. (2005:239). The level of ABC adoption among listed companies in South Africa is taken to be between 12\% (Sartorius et al., 2007:9) and 15.18\% (Wessels, 1999:43), because of the larger number of respondents that participated in these two surveys. There were 112 respondents in the survey done by Wessels (1999:43) and 181 respondents in the survey of Sartorius et al. (2007:5), whereas a much smaller number of respondents participated in the surveys conducted by Waweru et al. (2005:233) with 52 respondents and by Jacobs (2005:116) with 42 respondents. The larger the number of respondents, the more accurate is the conclusion that can be drawn of the population as a whole (Babbie \& Mouton, 2001:261).

\subsection{Factors that affect the adoption of $A B C$}

Shields and Young (1989:23-24) identified seven behavioural and organisational variables that are important during the implementation of cost management systems: (1) support from top management; (2) linking the cost management system to competitive strategies, in particular to quality and speed strategies; (3) linking the cost management system to compensation and performance appraisals; (4) sufficient internal resources (for example employee time); (5) training in designing, implementing and using cost management systems; (6) non-accounting ownership; and (7) agreement about and understanding of the objectives of the cost management systems.

Shields (1995:148) discovered that users' perceptions of $A B C$ were linked to six behavioural and organisational variables: top management's support, integration with competition strategy initiatives such as total quality management (TPM) and just in time (JIT), performance evaluation and compensation, non-accounting ownership of the $A B C$ project, training in the designing, implementing and using of $A B C$, and provision of adequate resources. Interestingly, technical characteristics of the system (that is, canned software, custom software, stand-alone system, external consultant) had no linkage to the successful implementation of ABC. McGowan and Klammer's (1997:234-235) results confirmed four of the variables identified by Shields (1995:148): top management support, the degree to which objectives are understood, the adequacy of training and training resources, and the linkage to the successful implementation of $A B C$. Their research found a positive relationship between user involvement and user perception of the quality of information produced with the successful implementation of $A B C$ (McGowan \& Klammer, 1997:235). Foster and Swenson (1997:122) further tested the variables identified by Shields (1995:148) to establish which of the variables had the highest explanatory power in determining the successful implementation of $A B C$. These variables were the following: integration with performance evaluation linked to compensation, links to quality initiatives, top management support, implementation and training, and resources.

The $A B C$ paradox is that the level of $A B C$ adoption has not grown as expected, despite the widely documented benefits of ABC. Gosselin's (1997:118-119) survey studied the effect of organisational structure and strategy on the adoption of $A B C$ and found that a formal 
organisation will be more likely to adopt $A B C$ than a decentralised, less formal organisation. Furthermore, he found that companies that adopted a prospector strategy would be more likely to adopt $A B C$ than companies that followed a defender, analyser or reaction strategy. The reason for this is that companies adopting a prospector strategy are more innovative in nature and have a willingness to adopt new management techniques (Gosselin, 1997:118-119). According to Baird, Harrison and Reeve (2004:394), a business culture which includes innovation, outcome orientation and tight versus loose control has a positive relationship with the level of $A B C$ adoption.

Drury and Tayles (2005:75) tried to explain the $A B C$ paradox by determining which variables in a company have a positive relationship with the adoption of $A B C$. Their survey found the level of product diversity, size, extent of standardisation/customisation of the product range, and the sector in which the company operates to have a positive relationship with the adoption of ABC. Variables that had no relationship with the adoption of $A B C$ were the level of competitiveness, cost structure and the importance of cost information for decision making (Drury \& Tayles, 2005:75). The finding regarding the size of a firm is widely supported in other surveys (Baird et al., 2004:394; Clarke, Hill \& Steven, 1999:451; Innes, Mitchell \& Sinclaire, 2000:352). However, a survey conducted by Cohen, Venieris and Kaimenaki (2005:997) found that the size of a firm had no relationship with whether ABC is adopted or not. Contrary to Drury and Tayles' (2005:75) finding that the importance of cost information for decision making has no relationship with the adoption of ABC, Baird et al. (2004:394) found a positive relationship. Lastly, Cohen et al. (2005:997) support the findings of Drury and Tayles (2005:75) that the intensity of competition and the company cost structure have no impact on whether $A B C$ is adopted or not.

\subsection{Problems with implementing $A B C$}

Sartorius et al. (2007:13-14) interviewed $A B C$ consultants to identify the problems that are encountered when implementing $A B C$. The following problems were cited by the majority of consultants: $A B C$ is too costly, it is difficult to collect the appropriate data, it is difficult to define cost pools and cost drivers, and the support of top management is sometimes lacking. The complexity associated with the implementation, the time taken to implement $A B C$, inadequate resources that increase the cost associated with $A B C$ adoption, and the difficulty in collecting the data needed to set up the $A B C$ system are also mentioned in international studies, which shows that these problems are not limited to South Africa (Anand, Sahay \& Saha, 2005:141; Clarke et al., 1999:457; Cohen et al., 2005:984). Wessels and Shotter (2000:222) found, on the contrary, that a lack of top management support was not highlighted as a major problem when implementing $A B C$ in South Africa. According to them, the following problems were mostly cited when implementing $A B C$ : inadequate training of users, inadequate training of managers, more emphasis being placed on other priorities in the firm and finally, the implementation being too time-consuming for operational managers. The impact of top management support on the successful implementation of $A B C$ is well researched and it has been proven that a strong correlation exists between the level of top management support and the successful implementation of ABC (Cotton, Jackman \& Brown., 2003:69-71; Innes et al., 2000:357-358). An explanation for this strong correlation could be that some managers will see no need for change without the support from top management and subordinates will see no need to carry on maintaining and using the $A B C$ system without top management using $A B C$ (Garrison, Noreen \& Seal, 2003:266). 
One anomaly in the survey conducted by Sartorius et al. (2007:13) is that the lack of adequate systems and IT was not identified as a significant problem by consultants, whereas surveys conducted in Greece, India, Canada and France found selecting adequate software to be a major problem in implementing ABC (Anand et al., 2005:141; Bescos, Cauvin \& Gosselin, 2002:236; Cohen et al., 2005:992). The reasons for the dissatisfaction are attributable to $A B C$ software not being user-friendly, the integration of the $A B C$ system with the main accounting system being difficult, the software lacking flexibility, and maintenance costs being high (Bescos et al., 2002:236). The reason for the low level of problems being experienced by respondents in the South Africa study may be that companies use normal Excel spreadsheets to run $A B C$, as well as standard ABC software (Bescos et al., 2002:236).

The low rate of $A B C$ adoption of between $12 \%$ and $15.18 \%$ suggests that $A B C$ is still in its infancy stage and therefore companies may still be using a very basic form of $A B C$ (Sartorius et al., 2007:9; Wessels, 1999:43).

\section{6 $\mathrm{ABC}$ in the health care environment}

The private medical inflation rate compounded over a three-year cycle was $10.9 \%$ at the end of 2012. This is $5.4 \%$ higher than the normal consumer price index and $3.4 \%$ higher than the medical inflation in the USA. The reasons for the high private medical inflation rate are the longer life expectancy of the elderly, the drop in the quality of public health care and the increase in demand for private health care (Discovery Health Medical Scheme, 2012:29).

As the largest private medical aid in South Africa, Discovery Health's portion of claims paid out to private health care facilities amounted to $30.84 \%$ of the total claims during 2011 and is the largest expense category in relation to all claims paid out (Discovery Health Medical Scheme, 2011:19). The increase in costs of private health care facilities therefore largely contributes to the high medical inflation rate.

Kaplan and Porter (2011:48) argue that the biggest cause of high health care costs is that poor costing systems are used that cannot accurately measure the cost per procedure. Without being able to effectively measure the cost of resources consumed to perform the health care procedures, it is impossible to effectively manage these costs and activities.

A study conducted on a sample of 277 health care facilities in the USA found that managers' evaluations of the relevance and usefulness of cost data positively correlated with the extent to which systems can provide greater detail, better classify cost according to behaviour, and frequently report on cost information (Pizzini, 2006:179). The study showed that health care facilities with such systems are significantly more profitable, generate better cash flow, and have lower administration costs (Pizzini, 2006:203). ABC is one such costing system, as it has the ability to provide greater costing detail and better cost classifications, and it can be run at regular intervals.

In a study undertaken in the USA by Lawson (2005:81), the ABC adoption rate during 1994 was found to be $16 \%$ in the health care sector, decreasing to $14 \%$ during 1999 , which was $6 \%$ lower than the adoption rate of $20 \%$ found by West and West (1997:22) in their survey in the USA and Canada. The adoption rate found by Lawson (2005:82) is also much lower than the adoption rates reported in a survey conducted in Ireland by Doyle, Duffy and McCahey (2007:8). In this survey $55 \%$ of the respondents indicated that they had implemented $A B C$. Most of the respondents $(83 \%)$ in the survey indicated that they adhered to the principles of $A B C$, while the remaining $17 \%$ had fully adopted $A B C$ (Doyle et al., 2007:8). Therefore the true adoption rate of 
$A B C$ is only $9 \%$ of the total respondents in the survey conducted by Doyle et al. (2007:8). In South Africa the only previous survey conducted on the level of $A B C$ adoption within private health care facilities was performed by Viljoen (1994:112) in 1994, who found the ABC adoption rate to be $1.2 \%$.

One of the benefits of $A B C$ is that it can be implemented in a wide variety of health care facilities, as evidenced below:

$A B C$ was introduced into a full-service renal dialysis clinic located in the United States of America. By linking resources consumed through the use of $A B C$ to the different treatments, they improved cost estimates, which, in turn, improved the profitability analysis per treatment and allowed for better decision making (West \& West, 1997:23).

In 1995, a study was conducted in a specialist oncology centre located in England to determine whether $A B C$ could deliver real benefits for management decision making, especially in the areas of quality, cost and performance management. More than 300 activities were identified across the oncology centre through a detailed activity analysis. The top $10 \%$ of activities gave rise to $50 \%$ of total cost and the top $28 \%$ gave rise to $80 \%$ of cost. This gave management of the oncology centre a clear understanding of the activities that brought about $80 \%$ of the cost and enabled them to better manage these activities (Aird, 1996:3).

The most cited benefit of $A B C$ adoption in a survey by Doyle et al. (2007:18) was that $A B C$ brought about more accurate patient costing. In second place, a further four reasons were cited by the same number of respondents: the adoption of $A B C$ improved insight into the activities that drive costs and affect cost behaviour, promoted better resource efficiency, brought about more accurate pricing, and highlighted non-value adding activities. Another benefit cited was that it encouraged continued improvement and total quality control due to planning and control being directed by activities. The findings of Doyle et al. (2007:18) support the argument of Ross (2004:17-18) that $A B C$ has the potential to improve managers' cost awareness, which will lead to better cost demand and quality management in the health care setting.

The problems faced in implementing $A B C$ in a health care facility are similar to those discussed under section 2.5 above. The collection of the data to set up $A B C$ has been highlighted by Udpa (1996:96), while King, Lapsley, Mitchell and Moyes (1994:148) found the complexity in defining cost pools and identifying activity drivers to be problematic when implementing $A B C$. These problems result in the process being labour intensive and time consuming (Dowless, 1997; James \& Canby, 1995). The top three problems identified by Lawson (2005:92) were: (1) selling the concept of $A B C$ to middle management, (2) selecting cost drivers and defining distinct activities and (3) inadequate computer support. Doyle et al. (2007:27-28) found the top three problems of implementing $A B C$ to be (1) difficulty associated with the information system, (2) inadequate computer support to implement the system and (3) selecting cost drivers.

Hill (2000:62) found that larger health care facilities in terms of the number of beds are more likely to make use of sophisticated costing systems (such as $A B C$ ) and they will benefit more from such a system as they can spread the fixed costs over more beds. Larger health care facilities can benefit from economies of scale since a significant part of the investment in a new costing system is typically a fixed cost and they have more resources to afford sophisticated cost systems. The more sophisticated costing systems such as $A B C$ may lead to better managerial decisions, but the benefits of those decisions may not offset costs associated with a more functional system (Pizzini, 2006:185). 
Pizzini (2006:203) suggested that health care costs can be significantly reduced only when the direct costs of patient care is contained and not by merely improving administration efficiencies. $A B C$ can provide detailed procedure costing information, but the buy-in of physicians is necessary, as they determine the amount of resources that is used to treat patients.

In order to ensure that physicians and health care facilities are on the same page, health care facilities should use implicit means to influence physicians' behaviour, such as incentives based on reduction in cost and resource usage when treating patients (Feldman, Sloan \& Paringer, 1981:169). Resources used by physicians decreased when health care facilities reported a set of information to physicians that provides a basis of comparison for their practice patterns, along with cost and financial information (Eldenburg, 1994:114). Eldenburg, Soderstrom, Willis and Wu (2010:223) found that physicians' behaviour changed and resource usage when treating patients improved if they are included in the development of the $A B C$ system.

\subsection{Questionnaire development}

This study was a replica study of surveys conducted by Lawson (2005) and Doyle et al. (2007:56). The questionnaire was based on the two surveys as they allowed for data comparison between the results of this study and the results of the surveys conducted in Ireland and the USA. Furthermore, using existing questionnaires that have been tested improved the reliability of the questionnaire used in this study.

The questionnaire used by Lawson (2005:80) was slightly different in the questions included therein to the one used in the 1994 survey, but the purpose of both questionnaires was the same: to study the use of $A B C$ by health care facilities. Doyle et al. (2007:5-6) drew mainly on the questionnaire used by Lawson in 1994. Doyle et al. (2007) made adjustments to the questionnaire used by Lawson in 1994 to address the research objectives set out by the survey.

From the literature review, it is clear that $A B C$ is suited to the health care industry and can positively affect the operations of health care facilities. With the increased focus on costs within the private health care industry by the public, the Minister of Health and the Competition Commission have emphasised the importance of determining the role that costing systems such as $A B C$ plays in the operations of these facilities. The only other survey conducted to determine the level of $A B C$ adoption in health care facilities was performed in 1994. Since 1994 there have been significant changes in the private health care system, which highlights the knowledge gap in terms of the extent that $A B C$ is used within the operations of private health care facilities.

\section{RESEARCH DESIGN}

\subsection{Research objectives}

This study's primary research objective was to determine the extent that $A B C$ is being used within the operations of private health care facilities in South Africa.

In order to achieve the primary research objective above, secondary research objectives were developed that support the accomplishment of the primary research objective. The secondary research objectives are listed below:

- To determine the type and size of the health care facilities that has adopted ABC. 
- To determine the types of $A B C$ software used by the different health care facilities.

- To determine the length of time that $A B C$ has been implemented in health care facilities.

- To understand the actual benefits that have been realised through the adoption of $A B C$.

- To identify the problems that were experienced when implementing ABC.

\subsection{Research methodology}

A quantitative research methods allows larger samples to be tested and for data to be collected from an outsider's view (Welman, Kruger \& Mitchell, 2005:9). As the private health care facility sample was large as well as geographically widely spread, a quantitative research method was ideal for this research study.

An empirical study was done, because the researcher had to collect and analyse primary data. The only other survey on the adoption of $A B C$ in private health facilities was conducted by Viljoen in 1994, and due to the changes in the private health care industry since 1994 the data was outdated.

A cross-sectional study was done to research $A B C$ adoption in private health care facilities at a certain point in time. This research method was followed due to the cost and time constraints on the study.

\subsection{Data collection strategy}

A survey strategy was adopted to collect the data through an online questionnaire because:

- the study is a replica study of surveys conducted by Doyle et al. (2007) in Ireland and Lawson (2005) in the USA. In order to compare the results of this study with the results found in Ireland and the USA, a survey research strategy needed to be followed.

- a survey research strategy allows for a large geographical area to be covered and a large sample to be surveyed in a cost-effective and timely manner (Babbie \& Mouton, 2001:263).

- the study aimed to measure the use of $A B C$ in the private health care industry and therefore the research strategy had to allow for standardised questions and measurement over the entire sample.

- a survey research strategy is associated with a deductive research approach and tends to be used for exploratory and descriptive research (Saunders, Lewis \& Thornhill, 2007:138). The current research study followed a deductive research approach and combined exploratory, descriptive, and explanatory research; thus the survey strategy was ideal.

Respondents were asked to rate the closed ended questions on a five point Likert rating scale ranging from (1) "strongly disagree" to (5) "strongly agree", with "neither agree nor disagree" at (3) being the midpoint. The Likert scale was used to allow comparability of responses to different questions and to decrease the time it took respondents to complete the questionnaire.

During the data collection phase of the study, the researcher found that the online survey allowed respondents to complete the survey in their own time, which increased the number of responses, as evidenced by the number of responses being completed over weekends and after working hours. The survey strategy also allowed the researcher to work from a central location for the duration of the data collection phase while administering the survey across the country to the sample of hospitals. This saved both time and costs. 


\subsection{Sample size}

The research study is a replica study of surveys conducted by Doyle et al. (2007) in Ireland and Lawson (2005) in the USA. Therefore, the sample sizes used in these two surveys were used as guidelines for the current sample size. Both surveys used questionnaires as the data collection tool; similarly, a survey questionnaire was used as this research study's data collection tool. Doyle et al. (2007:7) sent out questionnaires to 60 financial controllers in Irish health care facilities and Lawson (2005:80) sent the questionnaire to 404 chief health administrators of health care facilities in the USA.

The sample size which was decided on for this study was 81 private health care facilities and three hospital groups. The group responses were evaluated separately from the health care facility sample as the impact of $A B C$ at health care facility and group level was expected to be different.

The health care facilities were grouped into acute hospitals, mental health hospitals, day clinics and an "other" category. An acute hospital is defined as a short-term hospital that has facilities, medical staff and all necessary personnel to offer diagnosis, medical care and treatment of an extensive range of acute conditions, including injuries (Connecticut Department of Public Health Code, 2009:282). A psychiatric/mental health hospital provides treatment, care and rehabilitation services only for patients with mental illness (Mental Health Act 17, 2002:5). A day clinic is defined as a unit where non-emergency surgical procedures take place and patients are discharged within hours of the surgery (World Health Organisation, 2007:1). Acute hospitals will generally have a larger case mix than either the mental health hospital or day clinics. Mental health hospitals focus on mental illness and day clinics focus on non-emergency procedures. Viljoen (1994:94) found that the complexity of a health care facility's case mix affected the type of costing system implemented and the level of complexity of such a system. Based on these findings it was decided to analyse the health care facilities that adopted $A B C$ into these four classification categories.

This study made use of a probability sampling method, as it allows for a larger population to be sampled than when using a non-probability sample.

\subsection{Response rates}

The total number of respondents amounted to 32 health care facilities of which $31 \%$ indicated that they adopted $A B C$; the remaining $69 \%$ indicated that they either had not adopted $A B C$ or were considering adopting $A B C$. One out of the three hospitals groups indicated that they had adopted $A B C$. It should be noted that the number of health care facilities that indicated that they adopted $A B C$ is relatively small and this limitation means that generalisations need to be treated with caution.

The response rate at health care facility level was $40 \%$, which is higher than the $36 \%$ response rate in the study by Doyle et al. (2007:7) and the $14.5 \%$ in the study by Lawson (2005:80). The reason for the higher response rate is that the other two surveys were postal surveys, while this study's questionnaire was administered online. Using Qualtrics made it easier for the respondents to complete the questionnaire than using a postal survey (Saunders et al., 2007:358).

This study differentiated between health care facility responses and group level responses. The distinction was based on the expectation that $A B C$ will be utilised differently at a group and a 
health care facility level; this will in turn impact the benefits realised through the adoption of ABC. In South Africa $75 \%$ of private hospital beds are controlled by three dominant hospital groups (Matsebula \& Willie, 2007:163). This high level of influence by the hospital groups over the private health care industry means that understanding the level of $A B C$ utilisation in the operations and the benefits realised through the adoption of $A B C$ at a group level is very important.

\section{RESULTS}

\subsection{The adoption of $A B C$ by the type of health care facility}

Drury and Tayles (2005:75) found that organisations with more complex products were positively correlated to the adoption of $A B C$. The case mix will be the equivalent of product complexity in a health care facility.

TABLE 1: Breakdown of the different types of health care facilities that have adopted ABC

\begin{tabular}{lc}
\hline Type of health care facility & ABC adoption rates \\
\hline Acute hospitals & $70 \%$ \\
Mental health hospital & $10 \%$ \\
Day clinic & $10 \%$ \\
Other & $10 \%$ \\
\hline
\end{tabular}

Source: Authors' calculations and deductions

The case mix in each type of health care facility is different, and this directly impacts the level of the complexity of treatment. From TABLE 1 above one can see that acute hospitals make up the largest percentage of health care facilities that have adopted $A B C$, and they tend to have larger case mixes than the other types of health care facilities. A large case mix increases the complexity of the treatments offered at the acute hospital and in turn increases the need for more complex costing systems such as ABC. This would support Viljoen's (1994:94) argument that the complexity of a health care facility's case mix will affect the type of costing system implemented and the level of complexity of such a system.

\subsection{Different types of $A B C$ software used by the health care facilities}

It is important to identify the type of $A B C$ software that health care facilities use, as this will determine the complexity of data analysis that can be undertaken (Bescos et al., 2002:236). Bescos et al. (2002:236) argued that, although the commercial $A B C$ software and internally designed $A B C$ software are more expensive to implement, they allow for more complex $A B C$ models to be run. These models also allow for more data analysis to be performed than simpler software such as Excel spreadsheets (Bescos et al., 2002:236). 
TABLE 2: Breakdown of the different types of ABC software used by health care facilities

\begin{tabular}{|c|c|c|c|}
\hline \multicolumn{2}{|l|}{ Type of $A B C$ software } & \multicolumn{2}{|c|}{ Adoption rates } \\
\hline \multicolumn{2}{|l|}{ Commercial $A B C$ software } & \multicolumn{2}{|c|}{$30 \%$} \\
\hline \multicolumn{2}{|l|}{ Excel spreadsheets } & \multicolumn{2}{|c|}{$40 \%$} \\
\hline \multicolumn{2}{|c|}{ Internally designed software } & \multicolumn{2}{|c|}{$30 \%$} \\
\hline \multicolumn{4}{|c|}{$\begin{array}{l}\text { Sophisticated } A B C \text { software (commercial and internally designed software) is used by } 60 \% \text { of the } \\
\text { health care facilities and the remaining facilities make use of excel spreadsheets. This shows } \\
\text { that the majority of health care facilities will be able to run detailed } A B C \text { models and } \\
\text { calculations. }\end{array}$} \\
\hline \multicolumn{2}{|l|}{ TABLE 3: } & $\begin{array}{l}\text { ed in relation to th } \\
\text { d beds }\end{array}$ & of the health care \\
\hline \multirow{2}{*}{$\begin{array}{c}\text { Number of registered } \\
\text { beds }\end{array}$} & \multicolumn{3}{|c|}{ Types of $A B C$ software used } \\
\hline & $\begin{array}{c}\text { Commercial } A B C \\
\text { software }\end{array}$ & Excel spreadsheets & $\begin{array}{c}\text { Internally designed } \\
\text { software }\end{array}$ \\
\hline Between $250-299$ & $0 \%$ & $0 \%$ & $10 \%$ \\
\hline Between $200-249$ & $10 \%$ & $0 \%$ & $0 \%$ \\
\hline Between 150 - 199 & $10 \%$ & $10 \%$ & $0 \%$ \\
\hline Between $100-149$ & $10 \%$ & $10 \%$ & $0 \%$ \\
\hline Between 50 - 99 & $0 \%$ & $10 \%$ & $10 \%$ \\
\hline Between $20-49$ & $0 \%$ & $10 \%$ & $10 \%$ \\
\hline Less than 20 & $0 \%$ & $0 \%$ & $0 \%$ \\
\hline
\end{tabular}

Source: Authors' calculations and deductions

From TABLE 3 above one can see that the majority of sophisticated $A B C$ systems (internally designed software and commercial software) are being used by health care facilities with more than a 100 registered beds. This supports the findings by Hill (2001:21) that larger health care facilities (in terms of the number of beds) are more likely to make use of sophisticated costing systems from which they will benefit more, as they can spread the fixed costs over more beds. Larger health care facilities can benefit from economies of scale, since a significant part of the investment in a new costing system is typically a fixed cost and they have more resources to afford sophisticated cost systems. 
TABLE 4: Breakdown of the type of ABC software in relation to the type of health care facility

\begin{tabular}{lccc}
\hline \multirow{2}{*}{$\begin{array}{c}\text { Type of health care } \\
\text { facility }\end{array}$} & \multicolumn{3}{c}{ Types of ABC software used } \\
\cline { 2 - 4 } & $\begin{array}{c}\text { Commercial } A B C \\
\text { software }\end{array}$ & $\begin{array}{c}\text { Excel spreadsheets } \\
\text { Acute hospital }\end{array}$ & $\begin{array}{c}\text { Internally designed } \\
\text { software }\end{array}$ \\
Mental health hospital & 20 & 30 & $\%$ \\
Day clinic & 0 & 10 & 20 \\
Other & 10 & 0 & 0 \\
\hline
\end{tabular}

Source: Authors' calculations and deductions

TABLE 4 above shows that the majority of acute hospitals make use of sophisticated ABC software (internally designed software and commercial $A B C$ software), followed by excel spreadsheets. The reason for the majority of the acute hospitals making use of more sophisticated $A B C$ software is the larger case mixes offered in acute hospitals, which increases the need for a more complex costing system.

\section{TABLE 5: Breakdown of the type of $A B C$ software in relation to the length of time $A B C$ has been adopted}

\begin{tabular}{lccc}
\hline \multirow{2}{*}{$\begin{array}{c}\text { Length of time in years that } A B C \text { has } \\
\text { been adopted }\end{array}$} & $\begin{array}{c}\text { Types of } A B C \text { software used } \\
\text { software }\end{array}$ & $\begin{array}{c}\text { Exce/ spread } \\
\text { sheets }\end{array}$ & $\begin{array}{c}\text { Internally } \\
\text { designed software }\end{array}$ \\
\cline { 2 - 4 } More than 15 less than 17 & 10 & $\%$ & $\%$ \\
More than 7 less than 15 & 20 & 0 & 0 \\
More than 1 less than 7 & 0 & 10 & 30 \\
Greater than 6 months less than 1 & 0 & 10 & 0 \\
Less than 6 months & 0 & 10 & 0 \\
\hline
\end{tabular}

Source: Authors' calculations and deductions

One of the problems of adopting $A B C$ highlighted in the literature is its complexity and difficulty to collect the data to set up the $A B C$ systems, which results in the process being labour intensive and time consuming (Dowless, 1997; James \& Canby, 1995). Due to the length of time it takes to implement $A B C$ and the period of adjustment to effectively use the $A B C$ system, it is expected that health care facilities that have used $A B C$ for a longer period will likely use more sophisticated $A B C$ software than health care facilities that have adopted $A B C$ recently. The majority of health care facilities that used $A B C$ for more than seven years employ sophisticated $A B C$ software that allows them to run more complex $A B C$ scenarios and models. 


\subsection{Actual benefits realised through the adoption of $A B C$}

\subsubsection{Actual benefits at a health care facility}

The top three actual benefits that health care facilities realised through the adoption of $A B C$ in order of importance are: (1) improved insight into activities that drive costs and impact on cost behaviour, (2) more accurate patient costing, (3) promotion of resource efficiency, and (3) more accurate patient pricing, jointly third.

The actual benefits found in South Africa are not too dissimilar to those found by Doyle et al. (2007:19-20), namely (1) more accurate patient costing, jointly second (2) improved insight into activities that drive costs and impact cost behaviour; (2) promotion of resource efficiency, (2) more accurate patient pricing, and finally (2) highlighting non-value adding activities.

The only difference between the two studies is that 'highlighting non-value adding activities' came in at seventh position in the South Africa survey.

\subsubsection{Actual benefits at a hospital group level}

The group that adopted $A B C$ highlighted improved insight into the activities that drive costs and impact on cost behaviour as the biggest benefit that has been realised through the adoption of $A B C$. This was followed by the promotion of resource efficiency and continuous improvement thereof, total quality control due to planning, and control being directed at the activities.

There is a difference between the benefits found at a group level and at a health care facility level. This could be due to the different uses of $A B C$ at the two levels. The encouraging aspect is that the group is finding that $A B C$ promotes continuous improvement and total quality control due to planning and control being directed at activities. This indicates that $A B C$ could be used to identify continuous improvement initiatives across the group.

\subsection{Problems experienced when implementing $A B C$}

\subsubsection{Problems found when implementing $A B C$ at a health care facility level}

The top three problems that were identified are (1) difficulty in allocating costs to activities that directly drive and affect cost behaviour, (2) difficulty in selling the concept to doctors and medical staff, and (3) the lack of adequate resources to effectively implement ABC. All the reasons that were cited amongst the top three problems received a rating of below 3 on the Likert scale, which means that no definite conclusion could be drawn from the responses.

\subsubsection{Problems identified when implementing $A B C$ at a hospital group level}

At a group level, the two biggest problems identified were the difficulty in selling the concept to doctors and other medical staff and the inadequate computer system support to implement $A B C$. Other problems cited were the lack of adequate resources to effectively implement $A B C$, gathering the relevant information to set up the $A B C$ system, and finding adequate information systems.

\section{SUMMARY AND CONCLUSION}


The private health care industry is set for a time of uncertainty and change given the launch of the market inquiry by the Competition Commission; the uncertainty surrounding the impact that the $\mathrm{NHI}$ implementation will have on the sector and the possibility of fee regulation. The degree to which health care facilities will be able to cope and manage during this time will be dependent on their willingness to adopt and use innovative management tools and techniques, such as $A B C$.

This study found that $A B C$ is used extensively within the operations of private health care facilities as evidenced by the increase in the $A B C$ adoption rate from $1.2 \%$ in 1994 to $31 \%$ during 2013. This adoption rate is higher than those found by similar surveys conducted in both Ireland and the USA.

Of the health care facilities that adopted $A B C, 70 \%$ were acute hospitals and $60 \%$ have more than a 100 registered beds. Of these that adopted $A B C, 70 \%$ have been using it for more than seven years.

Sophisticated $A B C$ software (commercial and internally designed software) was utilised by $60 \%$ of health care facilities, and the remaining make use of excel spreadsheets.

The actual benefits at a heath care facility level that were realised through the adoption of $A B C$ in order of importance are: (1) improved insight into activities that drive costs and impact on cost behaviour, (2) more accurate patient costing, (3) promotion of resource efficiency and more accurate patient pricing. At a group level, improved insight into activities that drive cost and impact cost behaviour was identified as the most important benefit realised.

The identification of problems that were experienced when implementing $A B C$ was not achieved due to all the problems identified by the health care facilities that adopted $A B C$ to be rated, on average below 3 on the Likert scale. At a group level, the two biggest problems identified were the difficulty in selling the concept to doctors and other medical staff and the inadequate computer system support to implement $A B C$.

In conclusion, this study shows that private health care facilities are willing to adopt and use innovative management techniques and tools to face the challenging times ahead. Based on the high $A B C$ adoption rate and the actual benefits realised through the adoption of $A B C$, medical aids should consider basing tariff negotiation with private health care facilities on a cost plus percentage basis. This will force health care facilities to implement advanced costing systems such as $A B C$. Future research should focus on determining the extent to which time-driven activity-based costing is being used in the operations of both the private and public health care facilities in South Africa.

\section{LIST OF REFERENCES}

Aird, B. (1996). Activity based cost management in health care - another fad? International Journal of Health Care Quality Assurance, 9, pp. 16-19.

Anand, M., Sahay, B.S. \& Saha, S. (2005). Activity-based cost management practices in India: An empirical study. Decision (0304-0941), 32, pp. 123-152.

Babbie, દ. \& Mouton, J. (2001). The practice of social research. Cape Town: Oxford University Press. 
Baird, K.M., Harrison, G.L. \& Reeve, R.C. (2004). Adoption of activity management practices: A note on the extent of adoption and the influence of organizational and cultural factors. Management Accounting Research, 15, pp. 383-399.

Bateman, C. (2010). How will NHI affect my practice? Workshop seeks answers. South African Medical Journal, 100, pp. 350-352.

Bateman, C. (2013). Whistle blast on private healthcare's 'zero sum game'. South African Medical Journal, 103, p. 278.

Bescos, P.L., Cauvin, E. \& Gosselin, M. (2002). Activity based costing and activity based management: A comparison of the practices in Canada and in France. Comptabilite-Control-Audit, 8, pp. 229-244.

Clarke, P.J., Hill, N.T. \& Steven, K. (1999). Activity-based costing in Ireland: Barriers and opportunities for change. Critical Perspectives on Accounting, 10, pp. 443-468.

Clarke, P. \& Mullins, T. (2001). Activity based costing in the non-manufacturing sector in Ireland: A preliminary investigation. Irish Journal of Management, 22, pp. 1-19.

Cohen, S., Venieris, G. \&Kaimenaki, દ. (2005). ABC: adopters, supporters, deniers and unawares. Managerial Auditing Journal, 20, pp. 981-1000.

Cooper, R \& Kaplan, R.S. (1988). Measure costs right: Make the right decision. Harvard Business Review, Sept/Oct, pp. 96-103.

Cooper, R. \& Kaplan, R.S. (1998). Cost and effect using integrated cost systems to drive profitability and performance. Boston, MA: Harvard Business School Press.

Connecticut Department of Public Health. (2009). Connecticut Public Health Code.

Correia, C., Langfield-Smith, K., Thorne, H., Hilton, R.W. (2008). Management accounting: Information for managing and creating value. New York, NY: McGraw-Hill Education.

Cotton, D.J., Jackman, S. \& Brown, A. (2003). Note to a New Zealand replication of Innes et al. UK activity-based costing survey. Management Accounting Research, 14, pp. 67-72.

Department of Health. (2011). Green paper on National Health insurance.

Discovery Health Medical Scheme. (2011). Integrated annual financial statements.

Discovery Health Medical Scheme. (2012). Integrated annual financial statements.

Dowless, R.M. (1997). Using activity-based costing to guide strategic decision making. Healthcare Financial Management: Journal of the Healthcare Financial Management Association, 51, p. 86.

Doyle, G.A., Duffy, L. \& McCahey, M. (2007). An empirical study of adoption/non-adoption of activity based costing in hospitals in Ireland. Paper presented at the Administration Sciences Association of Canada, Dalhousie University, Canada, 24-27 May 2008. The authors recalculated the mean of the responses to determine the weighting of respondents' responses on the Likert scale for the various questions.

Drury, C. (2004). Management and Cost Accounting. London, UK: Thomson Learning.

Drury, C. \& Tayles, M. (2005). Explicating the design of overhead absorption procedures in UK organisation. The British Accounting Review, 37, pp. 47-84.

Eldenburg, L. (1994). The use of information in total cost management. Accounting Review, 69, pp. 96-121. 
Eldenburg, L., Soderstrom, N., Willis, V. \& Wu, A. (2010). Behavioural changes following the collaborative development of an accounting information system. Accounting, Organizations \& Society, 35, pp. 222-237.

Feldman, R., Sloan, F. \& Paringer, L. (1981). Compensation arrangements between hospitals and physicians. Bell Journal of Economics, 12, pp. 155-170.

Foster, G. \& Swenson, D.W. (1997). Measuring the success of activity-based cost management and its determinants. Journal of Management Accounting Research, 9, pp. 109-141.

Garrison, R.H., Noreen E, W. \& Seal, W. (2003). Management Accounting European Edition. Berkshire, UK: McGraw-Hill Education.

Gosselin, M. (1997). The effect of strategy and organizational structure on the adoption and implementation of activity-based costing. Accounting, Organizations \& Society, 22, pp. 105-122.

Hill, N.T. (2000). Adoption of costing systems in US hospitals: An event history analysis 1980-1990. Journal of Accounting and Public Policy, 19, pp. 41-71.

Holzer, H.P. \& Norreklit, H. (1991). Management accounting and control systems. Tjidschrift Voor Economie and Management, XXXVI, pp. 273-301.

Innes, J., Mitchell, F. \& Sinclaire, D. (2000). Activity-based costing in UK's largest companies: A comparison of 1994 to 1999 survey results. Management Accounting Research, 11, pp. 349-362.

Jacobs, L. (2005). The impact of the changing practitioner requirements on management accounting education of South African universities. Unpublished doctoral thesis. Pretoria: University of Pretoria.

James, B. \& Canby, I. (1995). Applying activity-based costing to healthcare settings. Healthcare Financial Management, 49, p. 1.

Kaplan, R.S. \& Porter, E.M. (2011). How to save the cost crises in healthcare. Harvard Business Review, September, pp. 47-64.

King, M., Lapsley, I., Mitchell, F. \& Moyes, J. (1994). Costing needs and practices in a changing environment: The potential for $\mathrm{ABC}$ in the NHS. Financial Accountability \& Management, 10, p. 143.

Lawson, R.A. (2005). The use of activity based costing in the healthcare industry: 1994 vs. 2004. Research in Healthcare Financial Management, 10, pp. 77-94.

Lukka, K. \& Granlund, M. (2002). The fragmented communication structure within the accounting academia: The case of activity-based costing research genres. Accounting, Organizations \& Society, 27, pp. 165-190.

Luther, R.G. \& Longden, S. (2001). Management accounting in companies adapting to structural change and volatility in transition economies: A South African study. Management Accounting Research, 12, pp. 299-320.

Makholwa, A. (2013a). Life is tough. Financial Mail. Johannesburg: BDFM.

Makholwa, A. (2013b). Seeking a remedy. Financial Mail. Johannesburg: BDFM.

Matsebula, T. \& Willie, M. 2007. Private hospital report.

Matsoso, M.P. \& Fryatt, R. (2013). National Health Insurance: The first 18 months. South African Medical Journal, 103, pp. 156-158.

McConville, D.J. (1993). Start with ABC. Industry Week, 242, pp. 33-36. 
McGowan, A.S. \& Klammer, T.P. (1997). Satisfaction with activity-based cost management implementation. Journal of Management Accounting Research, 9, pp. 217-237.

Mental Health Act No. 17 of 2002 of South Africa.

Pizzini, M.J. (2006). The relation between cost-system design, managers' evaluations of the relevance and usefulness of cost data, and financial performance: An empirical study of US hospitals.

Accounting, Organizations and Society, 31, pp. 179-210.

Ross, T.K. (2004). Analyzing health care operations using ABC. Journal of Health Care Finance, 30, pp. $1-20$.

Sartorius, K., Eitzen, C. \& Kamala, P. (2007). The design and implementation of activity based costing (ABC): A South African survey. Meditari Accounting Research, 15, p. 21.

Saunders, M., Lewis, P. \& Thornhill, A. (2007). Research methods for business students. Essex, UK: Pearson Education.

Shields, M.D. (1995). An empirical analysis of firms' implementation experiences with activity-based costing. Journal of Management Accounting Research, 7, pp. 148-166.

Shields, M.D. \& Young, S. (1989). A behavioural model for implementing cost management system. Journal of Cost Management, Winter, pp. 17-27.

Udpa, S. (1996). Activity-based costing for hospitals. Health Care Management Review, 21, pp. 8396.

Viljoen, M. (1994). Die toepassing van aktiwiteitsgebaseerde kosteberekening in privaat hospitale in Suid-Afrika. Unpublished thesis. Potchefstroom: PU vir CHO.

Wasserman, H. (2010). Doctor's Orders: Five ways to prepare for the NHI. Finance Week, 11 November. Waweru, N.M., Hoque, Z. \& Uliana, ع. (2005). A survey of management accounting practices in South Africa. International Journal of Accounting, Auditing and Performance Evaluation, 2, pp. 226-263.

Welman, C., Kruger, F. \& Mitchell, B. (2005). Research Methodology. Cape Town, SA: Oxford University Press.

Wessels, S. \& Shotter, M. (2000). Organisational problems in respect of implementation of activitybased costing in South Africa. Meditari Accounting Research, 8, pp. 215-227.

Wessels, S. (1999). The implementation of activity based costing in South Africa. Pretoria: University of Pretoria.

West, T.D. \& West, D.A. (1997). Applying ABC to healthcare. Management Accounting: Official

Magazine of Institute of Management Accountants, 78, pp. 22-33. 